\title{
Nurturing entrepreneurship
}

\author{
The Innovation Forum on Quantum Technologies aims to help academics start technology companies.
}

Research universities spawn original ideas, and start-ups are a major source of technological innovation. It would then seem only natural that some enterprising graduates, in particular those awarded with PhDs, aspire to jump from the academic environment to a business-oriented setting. Yet it has been argued that academic skills tend to be rather focused and can be at odds with the entrepreneurial spirit, which embodies more diverse talents and a business mindset. People trained in academia may not have had the best chances to develop soft skills, yet they more easily recur to the sort of out-of-thebox thinking that can lead to great ideas. Both academics and start-up founders are adept at problem solving, manage constant deadlines and odd working hours and, perhaps most importantly, are not afraid to navigate the unknown.

It is worth recalling that the backbone algorithm for the Google search engine was written by cofounders Larry Page and Sergey Brin when they were PhD students at Stanford University. Geordie Rose, one of the founders of the company D-Wave Systems that is developing quantum computers for high-speed computation, holds a $\mathrm{PhD}$ in theoretical physics. These are not just shooting-for-the-stars examples, but represent a trend of physics entrepreneurship, which has grown stronger in the past few years. A recent survey from the American Institute of Physics on entrepreneurship and innovation revealed that nearly one in eight $\mathrm{PhD}$ holders had founded their own company ${ }^{1}$. With prospective academic positions expected to absorb a mere $4 \%$ of today's PhD students ${ }^{2}$, physicists are drifting away from academia, and not only to traditional alternative career paths in teaching, industry and finance.

Of course, creating a successful start-up does not depend only on having a good idea. The reality is that nearly three out of four start-ups will not be able to return the capital invested in them ${ }^{3}$. The main challenges are timing, funding and connections. Several governments, having acknowledged the potential of start-ups for domestic economic growth, are taking steps to address these problems. For example, we recently discussed the UK approach to sustaining innovation (and in particular the $£ 270$-million-worth quantum technologies programme that aims to bring together the worlds of academia

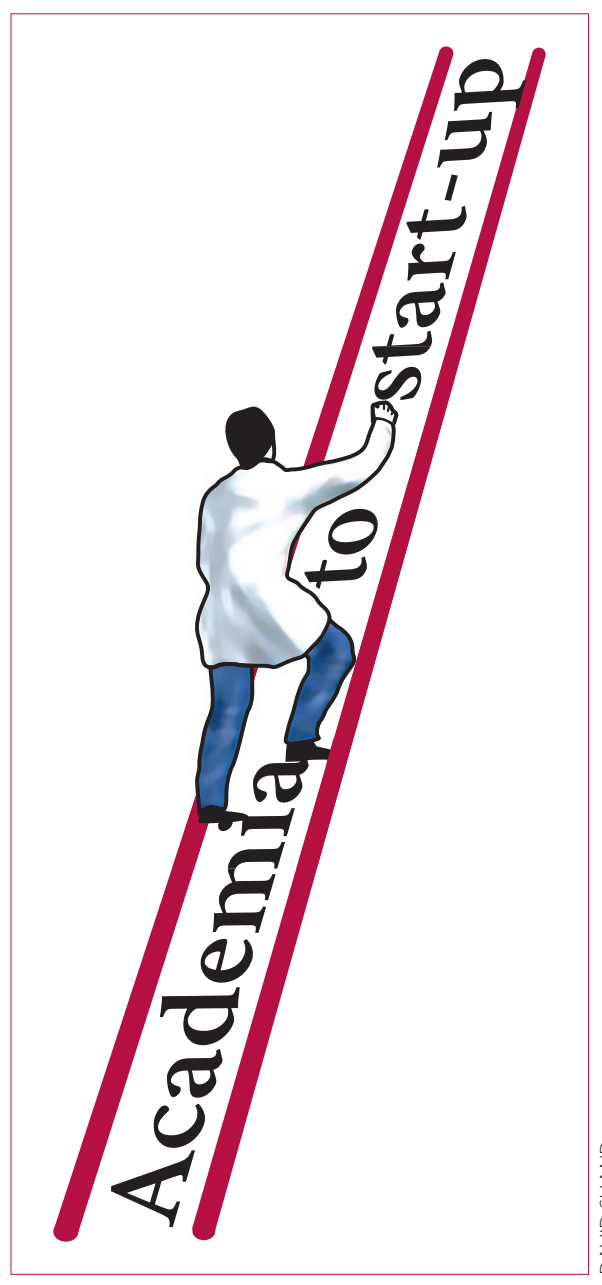

and industry) with Richard Murray from Innovate UK, a dedicated government innovation agency ${ }^{4}$.

Nature and Entrepreneur First (EF; http://www.joinef.com), in collaboration with Innovate UK, have now joined forces in organizing an Innovation Forum in Quantum Technologies (http://www.nature. $\mathrm{com} /$ nature/efinnovations/index.html). EF is a start-up company that helps technologists develop start-ups from scratch. Unlike most schools for founders however, EF recruits individuals based on talent and not just ideas. Through an intensive six-month programme, several handpicked individuals with technical background are being assisted by a network of seasoned entrepreneurs and computer-science academics to create viable businesses that are ready for seed funding. According to EF co-founder Alice Bentinck, "we want EF to attract the greatest concentration of technical talent and build the most exciting technology companies in Europe. By creating an environment where brilliant, young minds can flourish, we are helping to build the world-changing startups of tomorrow. If you are an ambitious and technically skilled individual that wants to make the most of your talent, then we want to hear from you."

The Nature/EF Forum is aimed primarily at young scientists with an entrepreneurial mindset and trained in quantum physics: five early-career researchers will be selected on the basis of their research experience and skills, motivation and ambition (regardless of their publication record). A solid idea for a start-up at the point of application is not a prerequisite for participation, nor is commercial experience. The application deadline is the 15th of January, while participants will be notified by mid-February. Over the course of the following two months, they will shape and promote their ideas for quantum technology-related start-ups, through coaching sessions with EF and Nature (in person or via telephone). The aim of this process is to make the ideas attractive for funding, and solid enough to survive in the real world. These ideas will in fact be put to the test on 6 May 2016, in the Nature headquarters in London. The applicants will have the opportunity to present them and receive useful feedback from a committee of invited investors, technology-transfer experts and experienced entrepreneurs.

At the moment, the call for submissions for the Innovation Forum for Quantum Technologies is still open. The world is always ready for a quantum revolution: those who believe they can lead it should apply.

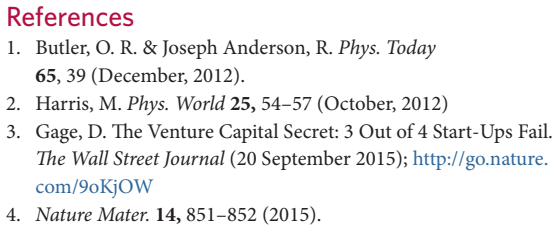

\section{Correction}

In the version of the Editorial 'A checklist for photovoltaic research' originally published (Nature Mater. 14, 1073; 2015), in ref. 2, the page number should have been ' 133 '. Corrected in the online versions after print 5 November 2015. 